Fetal Diagnosis

and Therapy
Fetal Diagn Ther 2008;23:303-307

DOI: $10.1159 / 000123618$
Received: February 8, 2007

Accepted after revision: April 22, 2007

Published online: April 14, 2008

\title{
Evaluation of Normal Fetal Branch Pulmonary Artery Diameters Measured by Ultrasonography: A Comparison with Congenital Diaphragmatic Hernia
}

\author{
Shuichi Katayama Katsuhiko Tada Yoshie Nakanishi Masayo Takata \\ Kazumasa Kumazawa Saya Tsukahara Eiko Takamaru \\ Department of Obstetrics and Gynecology, National Hospital Organization Okayama Medical Center, \\ Okayama, Japan
}

\section{Key Words}

Pulmonary artery $\cdot$ Pulmonary artery diameter •

Ultrasonography $\cdot$ Congenital diaphragmatic hernia .

Pulmonary hypoplasia

\begin{abstract}
Objective: The aim of this study was to examine the size of fetal branch pulmonary artery (PA) diameters in normal growth fetuses. Method: Fetal PA diameters were measured in 175 normal fetuses between 18 and 40 weeks of gestation from 2005 to 2006. In addition, 4 fetuses with left-sided congenital diaphragmatic hernia (CDH) from 2001 to 2006 were retrospectively reviewed. Branch PA diameters were measured from a cross-sectional image at the level of the threevessel view (main PA, ascending aorta and superior vena cava) to demonstrate the long axis of both branch PAs whenever possible. Results: Both the left and right PA diameters were found to correlate strongly with the advancing gestational age ( $r=0.78, p<0.01$, respectively). Left pulmonary artery to main pulmonary artery (LPA/MPA) ratio and right pulmonary artery to main pulmonary artery (RPA/MPA) ratio were calculated. These two parameters were almost constant throughout gestation. LPA in fetal left CDH was smaller than control. Both LPA/MPA and RPA/MPA were within the normal range in most cases. Conclusions: It is important to
\end{abstract}

establish the normal range of branch PA diameters and it appears to be useful to compare the branch PA diameters in normal fetuses with that in cases of pulmonary hypoplasia.

Copyright $\odot 2008$ S. Karger AG, Basel

\section{Introduction}

Pulmonary hypoplasia is the result of a developmental delay in pulmonary development, associated with high mortality, ranging from 52.4 to $87.5 \%$ and increased complications of air leak and persistent pulmonary hypertension $[1,2]$. Pulmonary hypoplasia is defined classically as a wet lung/body weight ratio of $<0.015$ before 28 weeks' gestation or $<0.012$ at 28 weeks or later $[3,4]$. The classical definition has only been demonstrated by autopsy. The clinical diagnosis is defined as immediate onset of severe respiratory insufficiency after birth requiring high ventilatory pressures and extreme clinical intervention complicated by pneumothoraces, pulmonary interstitial emphysema, and persistent pulmonary hypertension [1]. Despite the lethal outcome, there have been no reliable prenatal diagnostic methods for indicating the severity of pulmonary hypoplasia clinically.

Recent developments have provided effective methods for the measurement of branch pulmonary artery (PA)

\section{KARGER}

Fax +41613061234 E-Mail karger@karger.ch www.karger.com
(C) 2008 S. Karger AG, Basel

$1015-3837 / 08 / 0234-0303 \$ 24.50 / 0$

Accessible online at:

www.karger.com/fdt
Shuichi Katayama

Tamasu 1711-1, Okayama-shi

Okayama 701-1192 (Japan)

Tel. +81 86294 9911, Fax +81 862949255

E-Mail shukatayama@okayama3.hosp.go.jp 
diameters and PA Doppler waveform to determine the degree of pulmonary hypoplasia [5-9]. Sokol et al. [5] have proposed that fetal branch PA diameters correlated strongly with lung weights measured at autopsy.

This study measured the normal range of the diameter of the main pulmonary artery (MPA), left pulmonary artery (LPA), right pulmonary artery (RPA) in the fetus. This allowed the calculation of the LPA to MPA (LPA/ $\mathrm{MPA})$ ratio and RPA to MPA (RPA/MPA) ratio, which were independent of gestation. As a preliminary study, these branch PA diameters in the normal fetuses were compared with those in cases of congenital diaphragmatic hernia $(\mathrm{CDH})$, which has a poor prognosis caused by pulmonary hypoplasia, even if found prenatally [10].

\section{Methods}

Measurements were performed on a total of 175 mothers with singleton uncomplicated pregnancies at 18-40 weeks' gestation. They were measured for an internal diameter of MPA, LPA, and RPA including measurement of fetal growth. All patients were later delivered in our institution and displayed no anomalies in their neonates. Ultrasonography was performed by two sonologists.

Data were obtained using an Aloka SSD-3500 and SSD-5500 (Aloka Co., Tokyo, Japan) ultrasound system and a 3.5-MHz convex probe. LPA and RPA diameters were measured from frozen real-time images (fig. 1). All measurements were done in the absence of fetal body movements and fetal breathing movement. MPA and branch PA diameters were measured from a cross-sectional view through the fetal chest at the level of the three-vessel view (MPA, ascending aorta and superior vena cava). We visualized the long axis of branch PAs when possible.

To compare with the normal pulmonary artery diameter, we retrospectively investigated fetuses in $\mathrm{CDH}$. Five fetuses born at our institution between January 2001 and June 2006 were observed (table 1). Case 5 had right $\mathrm{CDH}$ with minor anomalies. The remainder had left $\mathrm{CDH}$ without other anomalies. All fetuses in $\mathrm{CDH}$ were delivered by elective cesarean section. The 3 neonates (cases 1-3) survived, while the other (case 4) died.

Data were analyzed with Deltagraph software release 5.0 (Statistical Analysis System, Monterey, Calif., USA) and expressed as mean $\pm \mathrm{SD}$

\section{Results}

Figure 2 shows the relationship between the fetal branch PA diameters and gestational age in our study. Both LPA and RPA diameters were significantly correlated with gestational age $(\mathrm{r}=0.78, \mathrm{p}<0.01$, respectively). We calculated LPA/MPA and RPA/MPA. These parameters were constant throughout gestation (LPA/MPA:

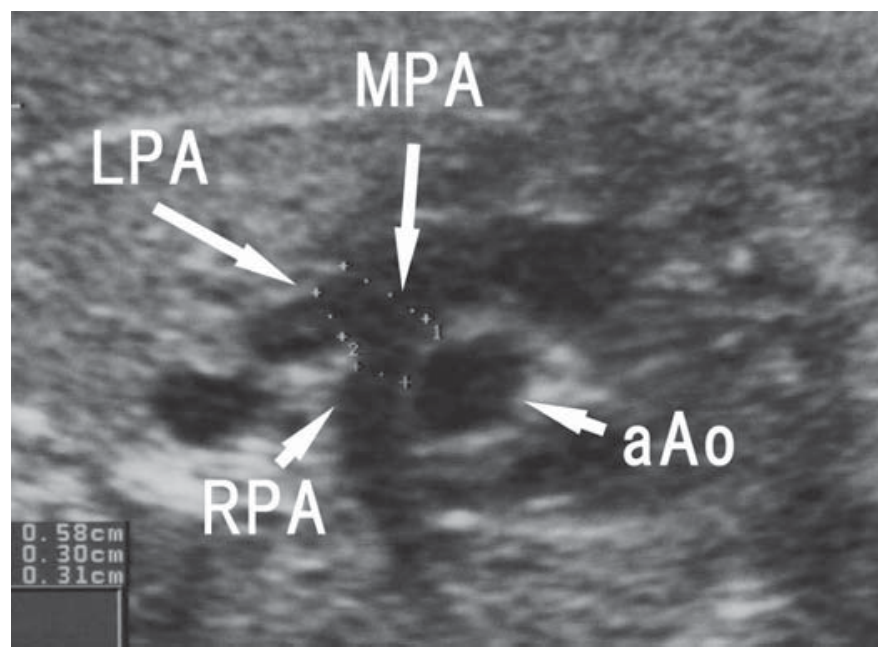

Fig. 1. Cross-sectional ultrasound image with a three-vessel view in a normal fetus. MPA = Main pulmonary artery; LPA = left pulmonary artery; $\mathrm{RPA}=$ right pulmonary artery; aAo = ascending aorta.

$0.47 \pm 0.07, \mathrm{RPA} / \mathrm{MPA}: 0.48 \pm 0.07$ ) (fig. 3). LPA/MPA, RPA/MPA, and branch PA diameters of 4 patients in $\mathrm{CDH}$ were plotted on the normogram (fig. 4,5 ). LPA diameter right before delivery was below the normal range in all cases. RPA diameter immediately preceding delivery was within the normal range in the surviving cases 1 and 3 , and under lower limit of the norm in case 2 who survived and case 4 who died. Two surviving patients in $\mathrm{CDH}$ (cases 2 and 3 ) were below the normal range in LPA/ MPA but were within the normal in RPA/MPA. Case 4, the patient who died, was within the normal range for both LPA/MPA and RPA/MPA, except for the RPA/MPA measurement at 32 weeks' gestation.

\section{Discussion}

Ultrasonography can be a non-invasive method to predict prenatal clinical pulmonary hypoplasia. To evaluate the degree of pulmonary hypoplasia, the lung-thoracic transverse area ratio $[11,12]$ and lung-head ratio [13-15] have been measured in patients with $\mathrm{CDH}$, and the thoracic circumference/abdominal circumference ratio has been used in patients with premature rupture of membrane $[16,17]$. Recently there have been some reports that pulmonary hypoplasia is related to the PA Doppler waveform [7, 9, 17-20]. However, it is so difficult to measure PA at a particular interrogation angle while, 


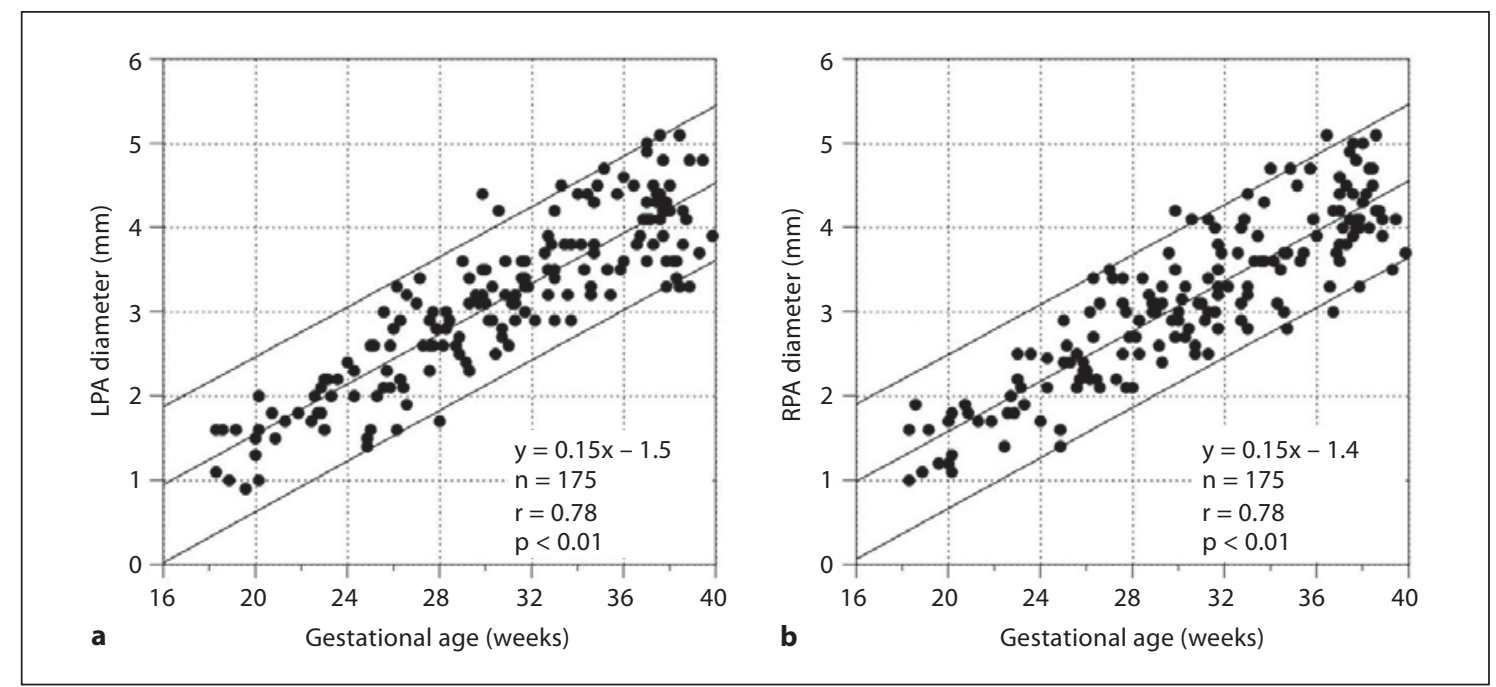

Fig. 2. a Individual values obtained in 175 normal fetuses with the $95 \%$ confidence intervals of the LPA diameter. b Individual values obtained in 175 normal fetuses and with the $95 \%$ confidence intervals of the RPA diameter. Both LPA and MPA diameters correlated strongly with advancing gestation.

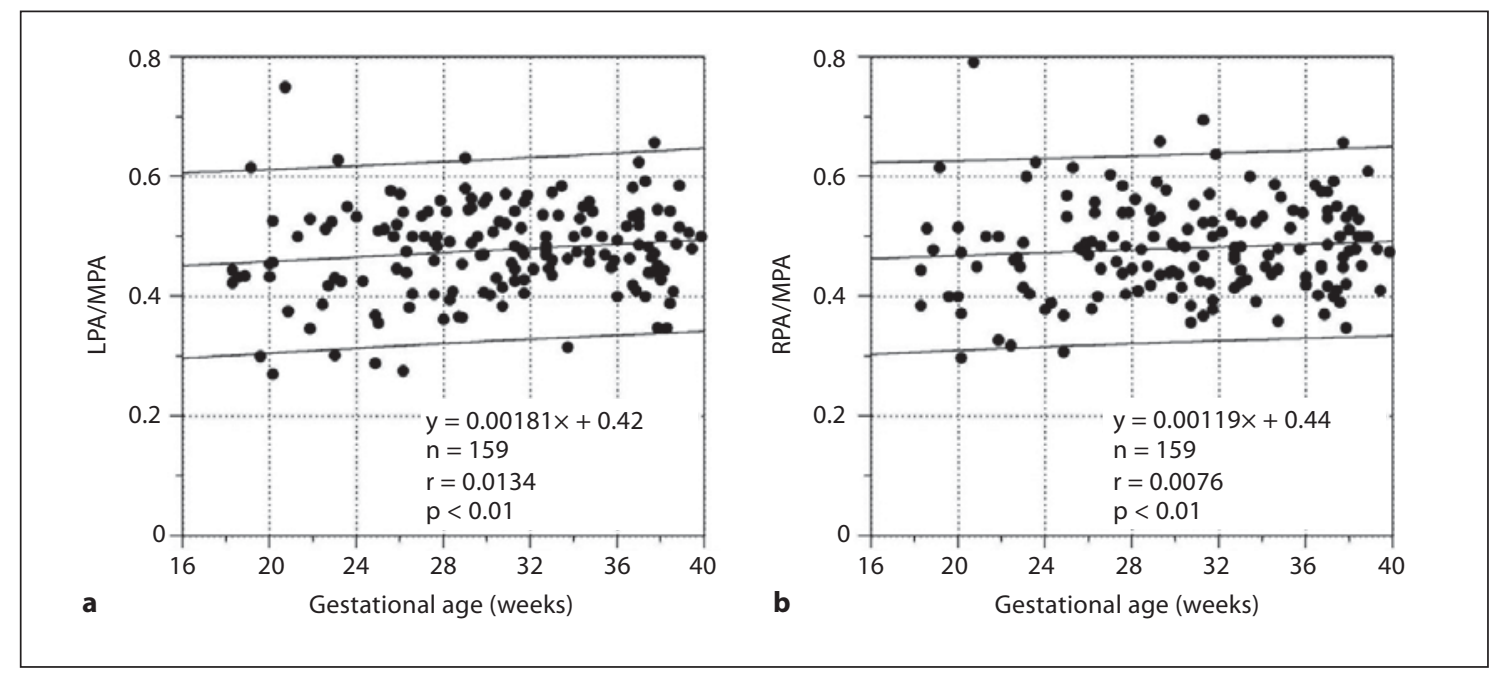

Fig. 3. a Change in LPA/MPA with gestational age with the $95 \%$ confidence intervals. b Change in RPA/MPA with gestational age and with the $95 \%$ confidence intervals. LPA/MPA was $0.47 \pm 0.07$ and RPA/MPA was 0.48 \pm 0.07. Both LPA/MPA and RPA/MPA were constant throughout gestation.

Table 1. Characteristics and outcomes of the fetuses in congenital diaphragmatic hernia

\begin{tabular}{|c|c|c|c|c|c|c|c|}
\hline Case & $\begin{array}{l}\text { Maternal age } \\
\text { years }\end{array}$ & $\begin{array}{l}\text { Gestational age } \\
\text { at onset, weeks }\end{array}$ & $\begin{array}{l}\text { Hernia } \\
\text { side }\end{array}$ & $\begin{array}{l}\text { Herniated } \\
\text { viscera }\end{array}$ & $\begin{array}{l}\text { Poly- } \\
\text { hydramnios }\end{array}$ & $\begin{array}{l}\text { Body weight at } \\
\text { delivery, } g\end{array}$ & Outcome \\
\hline 1 & 25 & 21 & left & intestine & - & 3,238 & survived \\
\hline 2 & 25 & 34 & left & intestine & - & 2,744 & survived \\
\hline 3 & 40 & 36 & left & intestine & - & 2,904 & survived \\
\hline 4 & 34 & 26 & left & intestine, liver & - & 2,820 & died \\
\hline 5 & 29 & 21 & right & intestine, liver & + & 2,520 & died \\
\hline
\end{tabular}


Fig. 4. The data points in cases of $\mathrm{CDH}$ are superimposed on previously derived 95\% confidence interval ranges for normal fetuses. a The LPA diameter was below the normal range in all cases prior to delivery. b RPA diameter was within the normal range in cases 1 and 3 who survived (s), and under lower limit of the normal in case 2 who survived and case 4 who died (d) at measurement right before delivery.

Fig. 5. a A scatterplot comparing the normal range of LPA/MPA. b A scatterplot comparing the normal range of RPA/ MPA. Data point in case 2 did not exist because MPA diameter was not measured. LPA/MPA was below the normal range in case 1 and 3 who survived (s) and within the normal range in case 4 who died (d). $\mathrm{RPA} / \mathrm{MPA}$ was within the normal range in cases 1-3 who survived. It was the same as in case 4 who died, except the measurement was performed at 32 weeks' gestation.
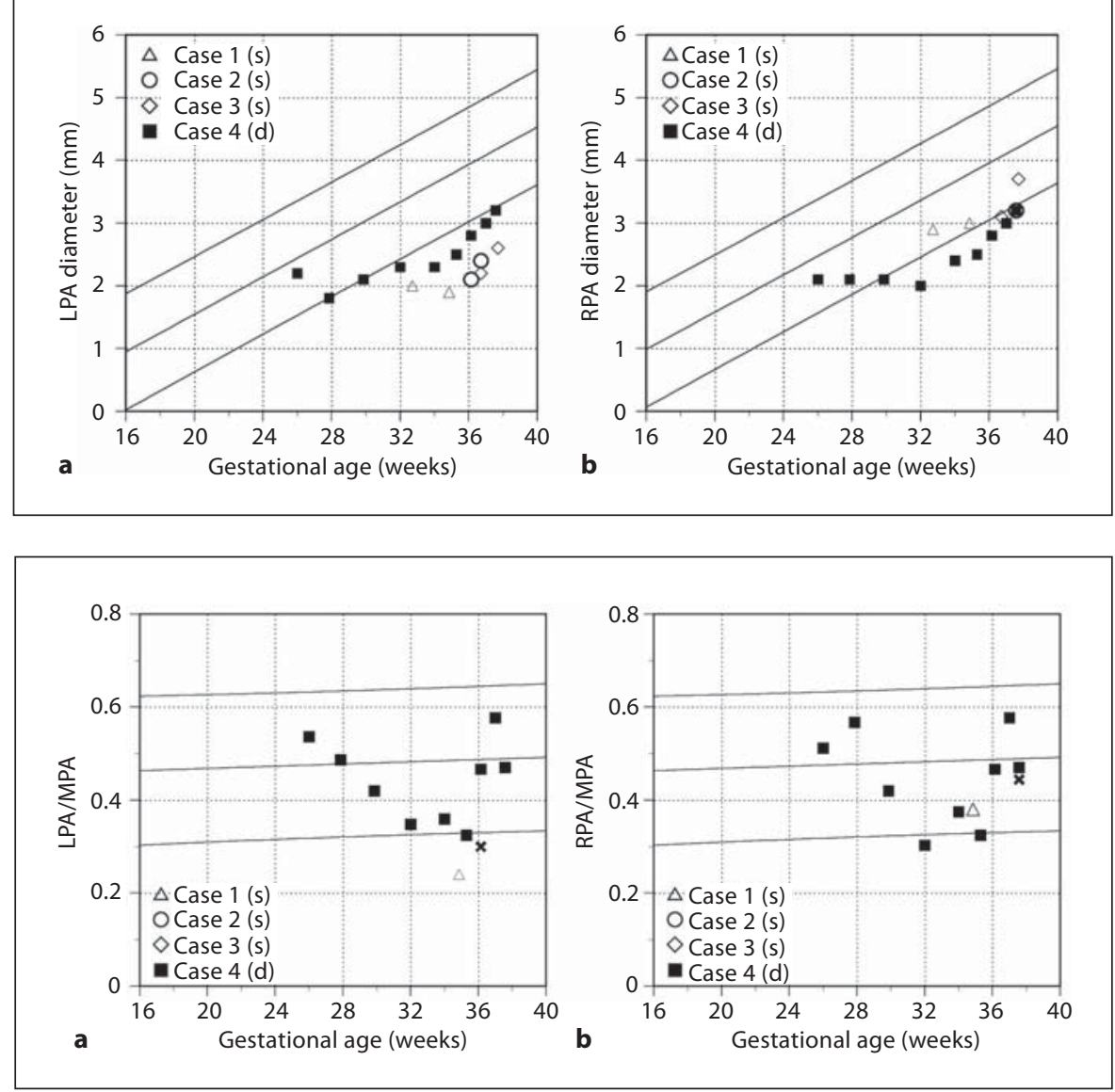

in addition, there is also a low reproducibility when using this method. However, there have been several reports suggesting a relationship between pulmonary hypoplasia and the PA diameter $[5,6,8]$.

Therefore, fetal branch PA diameter measurement is a potential method for evaluating pulmonary hypoplasia. This study investigated the normal range of LPA and RPA diameters. The normogram established an objective standard for comparison when pulmonary hypoplasia involving a fetal branch of pulmonary arteries of abnormal size is suspected. From this study, the branch PA diameters in normal fetuses were increased linearly with advancing gestation, and then the LPA diameter of $\mathrm{CDH}$ was below the normal range during the second half of pregnancy, whereas the RPA diameter was around the lower limit of normal.

In this study the MPA diameter was measured and the LPA/MPA and RPA/MPA ratios were calculated. These ratios were constant throughout normal gestation. Both LPA/MPA and RPA/MPA in patients with left lethal CDH were within the normal range in most gestational weeks. MPA diameter, as well as LPA and RPA diameters, in the patient with left $\mathrm{CDH}$ who died was also smaller than those who survived.

In conclusion, we suggest that the blood flow in the LPA decreased due to pressure from the herniated viscera and was distributed to the ductus arteriosus and RPA in cases with left $\mathrm{CDH}$. However, the RPA diameter could not increase by pressure due to heart deviation to the right. Increasing blood flow per unit area would cause injury to the pulmonary arterial wall and then the pulmonary arterial wall would lose elasticity. Therefore, the RPA diameter would be thus expected to demonstrate slow growth during gestation and the neonate would thus have persistent pulmonary hypertension after birth [21]. In severe CDH, MPA and branch PAs would also demonstrate slow growth during gestation. Bargy et al. [22] reported that, beyond 30 weeks' gestation, the distal pulmonary arterial wall becomes thicker on both sides in terminal cases with left $\mathrm{CDH}$ and that the weight of the 
right lungs in left $\mathrm{CDH}$ is significantly smaller than in normal fetuses. This indicates that it would be affected by both left and right pulmonary function despite left $\mathrm{CDH}$ at third trimester of pregnancy, which is in agreement with the measurements reported in this study. Unfortunately, many more cases of $\mathrm{CDH}$ are necessary to prove this suggestion. However, it seems to be useful to com- pare the branch PA diameters in normal fetuses with that in fetuses with $\mathrm{CDH}$.

In addition, in the case of prolonged preterm premature rupture of membrane and Potter syndrome, leading to pulmonary hypoplasia, the branch PA diameters might become smaller. Therefore, in consideration of pulmonary hypoplasia, the PA diameter must be considered.

\section{References}

-1 Nimrod G, Varela-Gittings F, Machin G, Campbell D, Wesenberg R: The effect of very prolonged membrane rupture on fetal development. Am J Obstet Gynecol 1984;148: 540-543.

2 Thibeault DW, Beatty EC Jr, Hall RT, Bowen SK, O'Neill DH: Neonatal pulmonary hypoplasia with premature rupture of fetal membranes and oligohydramnios. J Pediatr 1985; 107:273-277.

-3 Wigglesworth JS, Desai R: Use of DNA estimation for growth assessment in normal and hypoplastic fetal lungs. Arch Dis Child 1981; 56:601-605.

-4 Askenazi SS, Perlman M: Pulmonary hypoplasia: lung weight and radial alveolar count as criteria of diagnosis. Arch Dis Child 1979; 54:614-618

-5 Sokol J, Bohn D, Lacro RV, Ryan G, Stephens D, Rabinovitch M, Smallhorn J, Hornberger LK: Fetal pulmonary artery diameters and their association with lung hypoplasia and postnatal outcome in congenital diaphragmatic hernia. Am J Obstet Gynecol 2002;186: 1085-1090.

-6 Sokol J, Shimizu N, Bohn D, Doherty D, Ryan G, Hornberger LK: Fetal pulmonary artery diameter measurements as a predictor of morbidity in antenatally diagnosed congenital diaphragmatic hernia: a prospective study. Am J Obstet Gynecol 2006;195:470477.

7 Yoshimura S, Matsuzaki H, Miura K, Gotoh $\mathrm{H}$, Ishimaru T: Diagnosis of fetal pulmonary hypoplasia by measurement of blood flow velocity waveforms of pulmonary arteries with Doppler ultrasonography. Am J Obstet Gynecol 1999;180:441-446.
-8 Suda K, Bigras JL, Bohn D, Hornberger LK, McCrindle BW: Echocardiographic predictors of outcome in newborns with congenital diaphragmatic hernia. Pediatrics 2000;105: 1106-1109.

-9 Laudy JAM, Tibboel D, Robben SGF, Krijger RR, Ridder MAJ, Wladimiroff JW: Prenatal prediction of pulmonary hypoplasia: clinical, biometric, and Doppler velocity correlates. Pediatrics 2002;109:250-258

10 Harmath A, Hajdu J, Hauzman E, Pete B, Rona Z, Papp Z: Experiences in the perinatal management of congenital diaphragmatic hernia during the last 15 years in a tertiary referral institute. Fetal Diagn Ther 2007;22: 209-216.

-11 Metkus AP, Filly RA, Stringer MD, Harrison MR, Adzick NS: Sonographic predictors of survival in fetal diaphragmatic hernia. J Pediatr Surg 1996;31:148-152.

12 Yoshimura S, Masuzaki H, Hiraki K, Miura K, Nakayama D, Ishimaru T: Congenital diaphragmatic hernia: an evaluation of the prognostic value of the lung-to-head ratio. J Med Ultrasonics 2005;32:115-119.

13 Harrison MR: The fetus with a diaphragmatic hernia; in Harrison MR (ed): The Unborn Patient. Philadelphia, Saunders, 2001, pp 297-314.

14 Hasegawa T, Kamata S, Imura K, Ishikawa S, Okuyama H, Okada A, Chiba Y: Use of lungthorax transverse area ratio in the antenatal evaluation of lung hypoplasia in congenital diaphragmatic hernia. J Clin Ultrasound 1990;18:705-709.

15 Kamata S, Hasegawa T, Ishikawa S, Usui N, Okuyama H, Kawahara H, Kubota A, Fukuzawa M, Imura K Okada A: Prenatal diagnosis of congenital diaphragmatic hernia and perinatal care: assessment of lung hypoplasia. Early Hum Dev 1992;29:375-379.
16 Yoshimura S, Matsuzaki H, Fukuda H, Ishimaru T: Ultrasonographic prediction of lethal pulmonary hypoplasia: comparison of eight different ultrasonographic parameters. Am J Obstet Gynecol 1996;175:477-483.

17 Johnson A, Callan N, Bhutani VK, Colmorgen GHC, Weiner S, Bolognese RJ: Ultrasonic ratio of fetal thoracic to abdominal circumference: an association with fetal pulmonary hypoplasia. Am J Obstet Gynecol 1987;157:764-769.

18 Dillon PW, Cilley RE, Mauger D, Zachary C, Meier A: The relationship of pulmonary artery pressure and survival in congenital diaphragmatic hernia. J Pediatr Surg 2004;39: 307-312.

19 Mahieu-Caputo D, Aubry MC, Sayed MEI, Joubin L, Thalabard JC, Dommergues M: Evaluation of fetal pulmonary vasculature by power Doppler imaging in congenital diaphragmatic hernia. J Ultrasound 2004;23: 1011-1017.

20 Fuke S, Kanzaki T, Mu J, Wasada K, Takemura M, Mitsuda N, Murata Y: Antenatal prediction of pulmonary hypoplasia by acceleration time/ejection time ratio of fetal pulmonary arteries by Doppler blood flow velocimetry. Am J Obstet Gynecol 2002;188: 228-233.

21 Taira Y, Yamataka T, Miyazaki E, Puri P: Comparison of the pulmonary vasculature in newborns and stillborns with congenital diaphragmatic hernia. Pediatr Surg Int 1998; 14:30-35.

-22 Bargy F, Beaudoin S, Barbet P: Fetal growth in congenital diaphragmatic hernia. Fetal Diagn Ther 2006;21:39-44. 